\title{
Reduced serum albumin as a risk factor for poor prognosis in critically ill patients receiving renal replacement therapy
}

\author{
Lang Jing Zheng, Weiming Jiang, Lingling Pan and Jingye Pan*
}

\begin{abstract}
Background: Albumin is the primary body protein, which can predict the poor prognosis of several critical diseases. However, there are a few scientific studies on the relationship between albumin and the prognosis of dialysis patients. This study aims to explore the impact of hypoalbuminemia on the prognosis of critically ill patients with acute kidney injury (AKI) receiving continuous renal replacement therapy (CRRT).

Methods: This was a secondary study. Clinical, biochemical, and 28-day and 90-day mortality rates for critical patients with AKI who received CRRT between 2009 and 2016 were searched from the database to determine the effect of hypoalbuminemia on poor outcomes by univariate, multivariate, smooth curve fitting, and subgroup analysis.

Results: A total of 837 participants were enrolled in this study. Multivariate Cox proportional hazard regression analysis showed that hypoalbuminemia was associated with both 28-day and 90-day mortality risks after full adjustment for confounding variables, with an adjusted hazard ratio (95\% confidence interval) of 0.63 (0.50-0.80) and $0.63(0.51-0.78)$, respectively for each $1 \mathrm{~g} / \mathrm{dL}$ increase of albumin. Stratified analysis showed that hypoalbuminemia was not associated with poor prognosis in oliguria.

Conclusion: Hypoalbuminemia is associated with poor prognosis in critically ill AKI patients with CRRT; therefore, measuring albumin may be helpful for predicting the prognosis. However, in those with oliguria, this conclusion is not valid.
\end{abstract}

Keywords: Albumin, Acute kidney injury, Continuous renal replacement therapy, Mortality, Subgroup

\section{Introduction}

Acute kidney injury (AKI) is a health challenge worldwide [1]. More than 13 million individuals get affected by AKI annually, which occurs in more than $60 \%$ of intensive care unit (ICU) patients [2]. Approximately 5\% of ICU patients require continuous renal replacement therapy (CRRT) [3]. When the internal environment of patients with AKI is unstable, CRRT can easily control

\footnotetext{
* Correspondence: wmupanjingye@126.com

Department of Intensive Care Unit, The First Affiliated Hospital of Wenzhou Medical University, Wenzhou 325000, Zhejiang Province, People's Republic of China
}

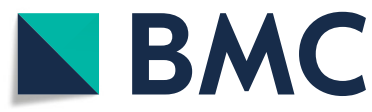

C C The Author(s). 2021 Open Access This article is licensed under a Creative Commons Attribution 4.0 International License, which permits use, sharing, adaptation, distribution and reproduction in any medium or format, as long as you give appropriate credit to the original author(s) and the source, provide a link to the Creative Commons licence, and indicate if changes were made. The images or other third party material in this article are included in the article's Creative Commons licence, unless indicated otherwise in a credit line to the material. If material is not included in the article's Creative Commons licence and your intended use is not permitted by statutory regulation or exceeds the permitted use, you will need to obtain permission directly from the copyright holder. To view a copy of this licence, visit http://creativecommons.org/licenses/by/4.0/ The Creative Commons Public Domain Dedication waiver (http://creativecommons.org/publicdomain/zero/1.0/) applies to the data made available in this article, unless otherwise stated in a credit line to the data. the imbalance. Therefore, CRRT is the most commonly used clinical renal replacement therapy $[4,5]$. The mortality of patients with AKI is quite high, particularly in those with severe AKI who require dialysis; the mortality can exceed 50\% [3]. Some clinical indicators, such as platelet, bilirubin, phosphate, Sequential Organ Failure Assessment (SOFA) score, and Acute Physiology and Chronic Health Evaluation II (APACHE II) score, have reportedly been related to the prognosis of critically ill patients with AKI [6-9].

Albumin is an important protein in the human body, which mainly exists in the blood, cerebrospinal, and 
lymphatic fluids. Albumin can not only maintain body nutrition and osmotic pressure but also combine with many insoluble substances, regulate the fluid exchange between various body parts, and affect blood circulation to the kidneys $[10,11]$. Albumin reduction can increase the rate of mortality in acute coronary syndrome, septic shock, heart failure, and other diseases [12-14]. The albumin decrease is caused by the body in the inflammatory state. When the body is damaged, inflammation will occur, resulting in the high expression of plateletderived growth factor, interleukin-6, and nitric oxideinduced vascular endothelial growth factor, which increase capillary permeability and angiogenesis, leading to the escape of albumin from the blood vessels $[15,16]$. Gradually decreasing serum albumin levels possibly lead to more severe inflammation [17]. Inflammation plays an important role in the development of AKI [18]. Current studies have shown that serum albumin level is associated with an increased incidence rate of AKI and mortality in such patients $[19,20]$. However, since the relationship between albumin levels and dialysis patient outcomes is controversial with only a few relevant studies [21, 22]; therefore, this study aimed to investigate the relationship between hypoalbuminemia and prognosis in patients with critical AKI under CRRT. The present study further investigated whether albumin affects mortality in specific populations with different CRRT indications.

\section{Materials and methods}

\section{Data source}

This study was a secondary analysis, with data from the 'DATADRYAD'open database. The data packages uploaded by the researchers in the database can be downloaded and quoted for free. This study refers to the data package uploaded by Jung et al. [23, 24].

\section{Study population}

Initially, a total of 2391 patients with AKI were enrolled in the study, all of whom received CRRT from January 2009 to September 2016 in the ICU of Yonsei University Health System Severance Hospital and the National Health Insurance Service Medical Center Ilsan Hospital. All participants met the Acute Kidney Injury Network criteria [25]. After analyzing the data of all participants, 281 with stage 1 AKI and 298 with stage 2 AKI were excluded. Also, the following populations were excluded: (1) minor patients $(n=42)$; (2) those with chronic kidney disease (CKD) or dialysis or CRRT history $(n=585)$; (3) those who were pregnant or lactating $(n=12)$; $(4)$ those with retrorenal obstruction $(n=263)$; (5) those with renal transplantation history $(n=64)$; and (6) those with albumin deficiency $(n=9)$. Finally, 837 patients were included in this study.
In the study published in the original data [23], Jung et al. showed that the study followed the declaration of Helsinki and was approved by the Yonsei University health system, Severance Hospital, and Institutional Review Committee. Owing to the de-identified data, the patient's written consent requirement was abandoned.

\section{Data collection}

This study collected demographic and clinical data of patients before CRRT, including age, sex, body mass index (BMI), comorbidities, and CRRT causes. The main causes of AKI, including sepsis, nephrotoxin, ischemia, surgery and so on, were also listed in this paper. The laboratory indices recorded at $0 \mathrm{~h}$ of CRRT in the ICU were $\mathrm{C}$-reactive protein (CRP), glomerular filtration rate (GFR), hemoglobin (Hb), white blood cell (WBC), serum creatinine $(\mathrm{CR})$, blood urea nitrogen (BUN), albumin (Alb), bicarbonate (HCO3-), potassium $(\mathrm{K}+)$, and phosphate. Also, scores on the severity of the patient's disease were collected, such as the Charlson comorbidity index (CCI), SOFA score, and APACHE II score.

\section{CRRT protocol}

Clinically, doctors would decide whether to initiate CRRT according to the degree of renal function damage in critically ill patients. Patients with uremia, persistent oliguria, volume overload, and decompensated metabolic acidosis should start CRRT as soon as possible. The femoral, internal jugular, and subclavian veins were selected as the central venous catheterization sites of CRRT. The multiFiltrate (Fresenius Medical Care, Bad Homburg, Germany) or the Prismaflex (Baxter International Inc. Lundia $\mathrm{AB}$, Sweden) machine was used for all patients. The initial CRRT blood flow velocity was $100 \mathrm{~mL} / \mathrm{min}$, which was increased to $150 \mathrm{~mL} / \mathrm{min}$. The total outflow of CRRT in all patients was targeted to deliver $\geq 35 \mathrm{~mL} / \mathrm{kg} / \mathrm{h}$.

\section{Statistical analysis}

Continuous variables following normal distribution were expressed as the mean \pm standard deviation, and skew variables were expressed as the median (quartile 1-quartile 3). Categorical variables were reported as the frequency or percentage. Box chart was used to show the relationship between serum albumin and different survival status, and analysis of variance was used to evaluate the difference between the survival and death groups. A univariate Cox proportional hazards model was established to analyze the risk relationship between albumin and 28-day and 90-day mortality in critically ill patients. Then, the multivariate Cox regression model was used to determine the independent effect of albumin on short-term and medium-term prognosis in critically ill patients. To ensure the robustness of the analysis results, 
this study not only gives the results of unadjusted, slight adjustment, and comprehensive adjustment analyses, but also converts albumin into classified variables for analysis according to the quartile method, and calculates the $p$-value of the trend to observe the possibility of nonlinearity. According to the indication of CRRT and the etiology of AKI, subgroup analysis was performed to further determine the relationship between albumin and short-term and medium-term prognosis. In order to explore whether there is a nonlinear relationship between albumin and prognosis, after adjusting all covariates, the correlation fitting curve between albumin and 28 and 90 day mortality was drawn by using the restrictive cubic spline function following on Cox proportional hazards models. In this study, $P<0.05$ was considered a significant difference.

In the present study, the variable CCI was transformed into continuous variable processing, and all data were processed using EmpowerStats (www.empowerstats.com, $\mathrm{X} \& Y$ solutions, inc. Boston, Massachusetts) and statistical packages R (http://www.R-project.org; The R Foundation; version 3.4.3).

\section{Results}

\section{Baseline characteristics of participants}

Table 1 lists the general characteristics of the included participants. The average age of the study participants was $62.57 \pm 14.42$ years, and $62.25 \%$ were men. The mean BMI and mean arterial pressure (MAP) were $23.90 \pm 4.83 \mathrm{~kg} / \mathrm{m} 2$ and $76.78 \pm 14.51$ $\mathrm{mmHg}$, respectively. Most of the critically ill patients had complications, including 406 (48.51\%) patients with hypertension, $266(31.82 \%)$ with diabetes, 112 (13.38\%) with congestive heart failure, and 90 (10.78\%) patients with cerebrovascular disease. Also, the prevalence of peripheral vascular disease, chronic obstructive pulmonary disease (COPD), myocardial infarction, and dementia was 29 (3.46\%), 51 (6.09\%), 75 (8.96\%), and 26 (3.11\%), respectively. Among the 837 participants, the 28 -day and the 90 -day mortality rate was 61.89 and $71.92 \%$, respectively. The box chart showed that serum albumin level was correlated with different survival statuses of 28 days and 90 days, and the serum albumin level of the survival group was significantly higher than that of the death group (both $p<0.001$ ) (Figs. 1 and 2).

\section{Univariate analysis}

As shown in Tables 2 and 3, Univariate analysis showed that albumin was associated with 28-day and 90-day mortality in critically ill patients. The hazard ratio (HR) and $95 \%$ confidence interval $(\mathrm{CI})$ were $0.66(0.57,0.76)$ and $0.62(0.55,0.71)$, respectively. Albumin was a protective factor. Also, the univariate analysis found that
Table 1 Baseline characteristics of participants

\begin{tabular}{|c|c|}
\hline Characteristics & Values \\
\hline Age, year & $62.57 \pm 14.42$ \\
\hline SEX (male/female) & $521 / 316$ \\
\hline $\mathrm{BMl}, \mathrm{kg} / \mathrm{m} 2$ & $23.90 \pm 4.83$ \\
\hline MAP, $\mathrm{mmHG}$ & $76.78 \pm 14.51$ \\
\hline Myocardial infarction, n (\%) & $75(8.96 \%)$ \\
\hline Congestive heart failure, $\mathrm{n}(\%)$ & $112(13.38 \%)$ \\
\hline Cerebrovascular disease, n (\%) & 90 (10.78\%) \\
\hline Peripheral vascular disease, n (\%) & $29(3.46 \%)$ \\
\hline Dementia, n (\%) & $26(3.11 \%)$ \\
\hline Diabetes, n (\%) & $266(31.82 \%)$ \\
\hline Hypertension, n (\%) & $406(48.51 \%)$ \\
\hline COPD, n (\%) & $51(6.09 \%)$ \\
\hline Mechanical ventilation, n (\%) & $661(78.97 \%)$ \\
\hline $\mathrm{K}+, \mathrm{mEq} / \mathrm{L}$ & $4.72 \pm 1.10$ \\
\hline HCO3-, mEq/L & $16.54 \pm 5.65$ \\
\hline Phosphate, g/dL & $5.94 \pm 2.53$ \\
\hline CRP, g/L & $66.45(18.88-164.80)$ \\
\hline$W B C, \mu \mathrm{L}$ & $11,840.00(6565.00-18,672.50)$ \\
\hline $\mathrm{HBIG} / \mathrm{dL}$ & $9.66 \pm 2.28$ \\
\hline Albago/dL & $2.61 \pm 0.59$ \\
\hline BUN, g/dL & $52.00(35.00-76.00)$ \\
\hline $\mathrm{Cr}, \mathrm{mg} / \mathrm{dL}$ & $3.02 \pm 1.74$ \\
\hline $\mathrm{GFR}, \mathrm{mL} / \mathrm{min}$ & $23.30(15.10-35.80)$ \\
\hline APACHE II score & $27.58 \pm 7.89$ \\
\hline SOFA score & $12.53 \pm 3.50$ \\
\hline $\mathrm{CCl}$ & $3.13 \pm 2.25$ \\
\hline \multicolumn{2}{|l|}{ AKI causes } \\
\hline Sepsis & $580(69.30 \%)$ \\
\hline Nephrotoxin & $26(3.11 \%)$ \\
\hline Ischemia & $65(7.77 \%)$ \\
\hline Surgery & 70 (8.36\%) \\
\hline Others & 96 (11.47\%) \\
\hline
\end{tabular}

CRRT causes

$\begin{array}{ll}\text { Volume overload } & 108(12.90 \%) \\ \text { Metabolic acidosis } & 183(21.86 \%) \\ \text { Hyperkalemia } & 39(4.66 \%) \\ \text { Uremia } & 93(11.11 \%) \\ \text { Oliguria } & 219(26.16 \%) \\ \text { Other } & 195(23.30 \%) \\ \text { 28-d mortality } & 518(61.89 \%) \\ \text { 90-d mortality } & 602(71.92 \%)\end{array}$

Data are expressed as $n(\%)$ or the mean $\pm S D$ or median (quartile 1-quartile 3) SD Standard deviation 


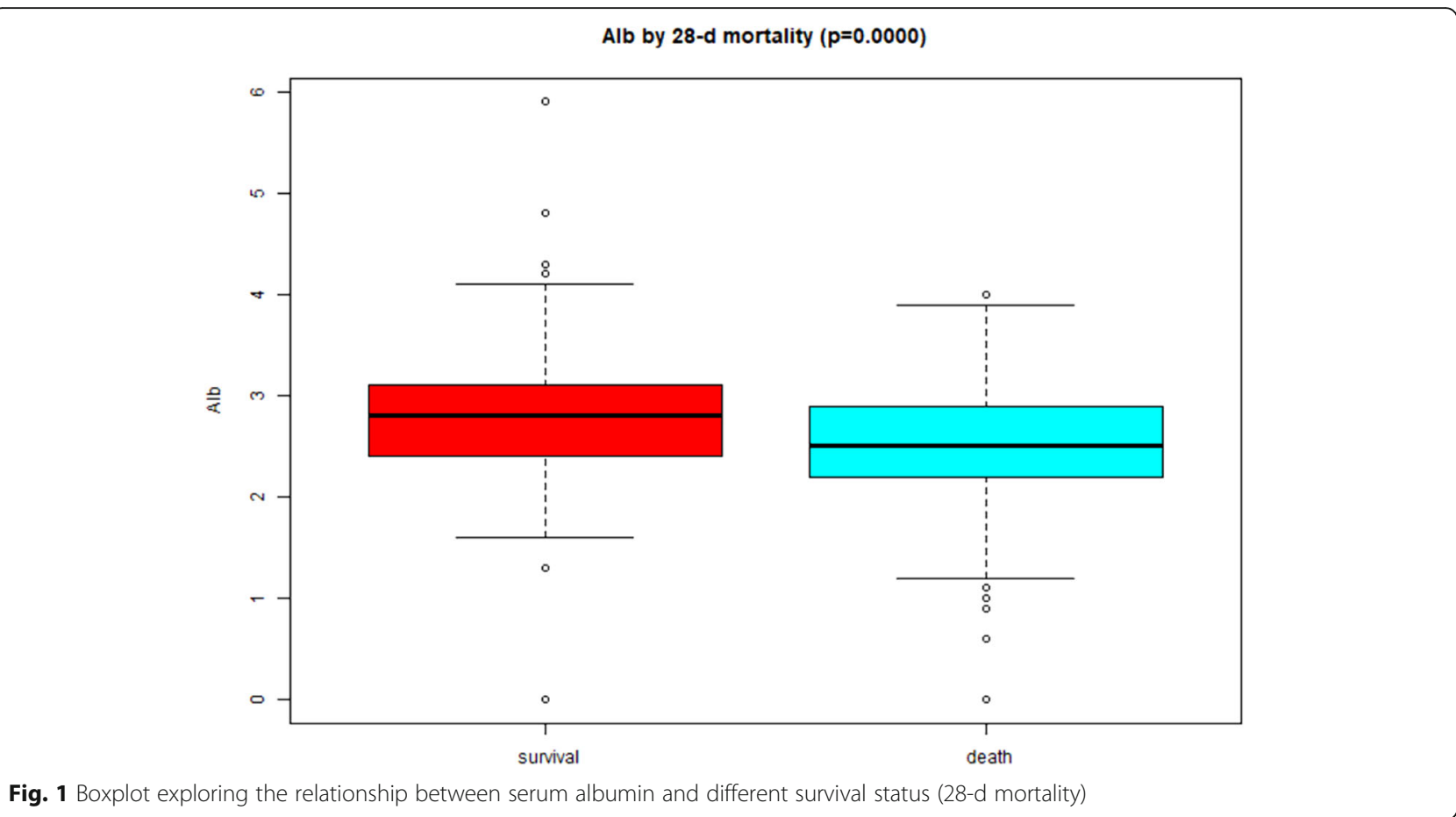

hypertension, APACHE II score, SOFA score, CCI, phosphate, MAP, mechanical ventilation, $\mathrm{Hb}, \mathrm{Cr}$, and GFR were associated with short-term and medium-term prognosis of critically ill AKI patients with CRRT, while BMI was only associated with 90-day mortality.

\section{Multivariate cox regression analysis}

To further clarify the relationship between albumin and short-term and medium-term prognosis, we established three models of unadjusted, micro adjusted, and fully adjusted in multivariate regression analysis. The results of

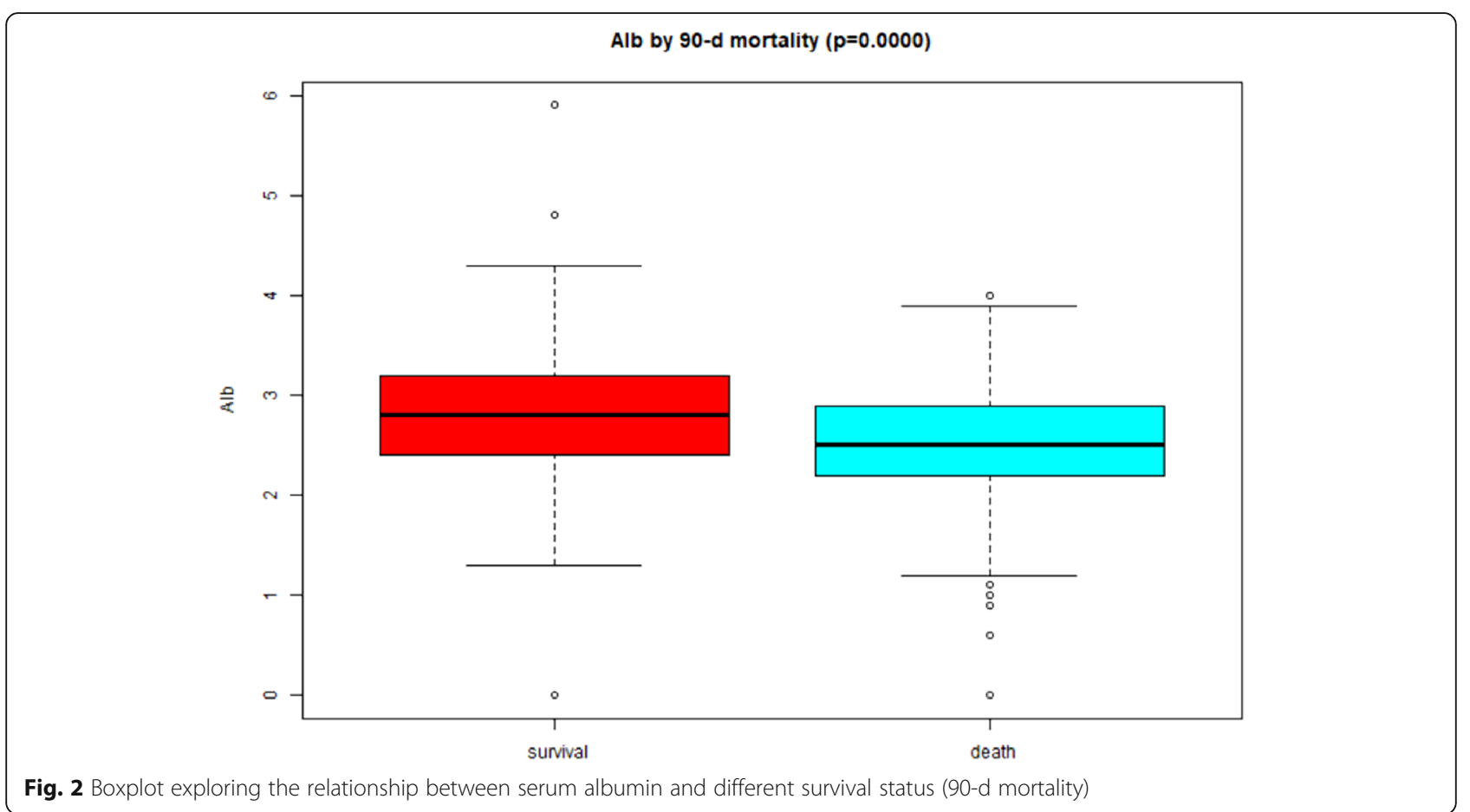


Table 2 The results of univariate analysis of 28-day mortality

\begin{tabular}{|c|c|c|c|c|c|}
\hline Variable & HR $(95 \% \mathrm{Cl})$ & $p$-value & Variable & HR $(95 \% \mathrm{Cl})$ & $p$-value \\
\hline Age & $1.00(0.99,1.01)$ & 0.9847 & Age & $1.00(1.00,1.01)$ & 0.4307 \\
\hline SEX & & & SEX & & \\
\hline male & 1.0 & & male & 1.0 & \\
\hline female & $0.94(0.78,1.12)$ & 0.4792 & female & $0.96(0.82,1.14)$ & 0.6630 \\
\hline Myocardial infarction & $0.99(0.74,1.33)$ & 0.9567 & Myocardial infarction & $0.93(0.70,1.24)$ & 0.6179 \\
\hline Congestive heart failure & $0.80(0.61,1.04)$ & 0.0947 & Congestive heart failure & $0.90(0.71,1.14)$ & 0.3679 \\
\hline Cerebrovascular disease & $0.90(0.68,1.19)$ & 0.4633 & Cerebrovascular disease & $1.02(0.79,1.33)$ & 0.8560 \\
\hline Peripheral vascular disease & $0.76(0.46,1.25)$ & 0.2844 & Peripheral vascular disease & $0.94(0.60,1.47)$ & 0.7887 \\
\hline Dementia & $0.71(0.42,1.20)$ & 0.1998 & Dementia & $0.87(0.53,1.40)$ & 0.5580 \\
\hline Diabetes & $0.91(0.76,1.10)$ & 0.3334 & Diabetes & $0.87(0.73,1.04)$ & 0.1202 \\
\hline Hypertension & $0.69(0.58,0.83)$ & $<0.0001$ & Hypertension & $0.72(0.61,0.84)$ & $<0.0001$ \\
\hline COPD & $0.91(0.62,1.32)$ & 0.6039 & COPD & $0.94(0.67,1.32)$ & 0.7179 \\
\hline K+ & $1.03(0.95,1.12)$ & 0.4208 & K+ & $1.07(0.99,1.15)$ & 0.0922 \\
\hline APACHE II score & $1.03(1.02,1.04)$ & $<0.0001$ & APACHE II score & $1.03(1.02,1.04)$ & $<0.0001$ \\
\hline $\mathrm{CCl}$ & $1.10(1.06,1.14)$ & $<0.0001$ & $\mathrm{CCl}$ & $1.07(1.04,1.11)$ & $<0.0001$ \\
\hline SOFA score & $1.17(1.14,1.21)$ & $<0.0001$ & SOFA score & $1.13(1.10,1.15)$ & $<0.0001$ \\
\hline CRRT causes & & & CRRT causes & & \\
\hline Volume overload & 1.0 & & Volume overload & 1.0 & \\
\hline Metabolic acidosis & $1.45(1.06,1.99)$ & 0.0207 & Metabolic acidosis & $1.41(1.05,1.87)$ & 0.0205 \\
\hline Hyperkalemia & $1.66(1.05,2.61)$ & 0.0285 & Hyperkalemia & $1.78(1.18,2.70)$ & 0.0063 \\
\hline Uremia & $0.94(0.65,1.38)$ & 0.7674 & Uremia & $1.08(0.77,1.52)$ & 0.6628 \\
\hline Oliguria & $1.08(0.78,1.47)$ & 0.6515 & Oliguria & $1.14(0.86,1.52)$ & 0.3584 \\
\hline Other & $1.45(1.06,1.98)$ & 0.0199 & Other & $1.32(0.99,1.75)$ & 0.0596 \\
\hline AKI causes & & & AKI causes & & \\
\hline Sepsis & 1.0 & & Sepsis & 1.0 & \\
\hline Nephrotoxin & $1.06(0.66,1.70)$ & 0.8108 & Nephrotoxin & $0.96(0.60,1.54)$ & 0.8664 \\
\hline Ischemia & $1.06(0.76,1.47)$ & 0.7251 & Ischemia & $1.01(0.75,1.37)$ & 0.9277 \\
\hline Surgery & $0.81(0.58,1.15)$ & 0.2370 & Surgery & $0.67(0.49,0.93)$ & 0.0151 \\
\hline Others & $1.32(1.00,1.72)$ & 0.0464 & Others & $0.90(0.70,1.17)$ & 0.4399 \\
\hline $\mathrm{HCO}-$ & $0.99(0.97,1.01)$ & 0.3030 & $\mathrm{HCO}_{-}-$ & $0.99(0.98,1.01)$ & 0.4557 \\
\hline Phosphate & $1.05(1.02,1.08)$ & 0.0018 & Phosphate & $1.04(1.01,1.08)$ & 0.0054 \\
\hline $\mathrm{BMI}$ & $0.98(0.96,1.00)$ & 0.0626 & BMI & $0.98(0.96,1.00)$ & 0.0163 \\
\hline MAP & $0.98(0.98,0.99)$ & $<0.0001$ & MAP & $0.98(0.98,0.99)$ & $<0.0001$ \\
\hline Mechanical ventilation & $2.12(1.65,2.73)$ & $<0.0001$ & Mechanical ventilation & $1.97(1.58,2.46)$ & $<0.0001$ \\
\hline WBC & $1.00(1.00,1.00)$ & 0.1276 & WBC & $1.00(1.00,1.00)$ & 0.2207 \\
\hline $\mathrm{Hb}$ & $0.93(0.90,0.97)$ & 0.0004 & $\mathrm{Hb}$ & $0.93(0.90,0.97)$ & 0.0002 \\
\hline BUN & $1.00(1.00,1.00)$ & 0.8286 & BUN & $1.00(1.00,1.00)$ & 0.5005 \\
\hline $\mathrm{Cr}$ & $0.89(0.84,0.94)$ & $<0.0001$ & $\mathrm{Cr}$ & $0.89(0.84,0.93)$ & $<0.0001$ \\
\hline Alb & $0.66(0.57,0.76)$ & $<0.0001$ & Alb & $0.62(0.55,0.71)$ & $<0.0001$ \\
\hline CRP & $1.00(1.00,1.00)$ & 0.8429 & CRP & $1.00(1.00,1.00)$ & 0.8145 \\
\hline GFR & $1.00(1.00,1.01)$ & 0.0256 & GFR & $1.01(1.00,1.01)$ & 0.0003 \\
\hline
\end{tabular}

Table 3 The results of univariate analysis of 90-day mortality 
the unadjusted model (model 1) showed that albumin was negatively correlated with 28-day and 90-day mortality. In model 2 (adjusted for age and sex only), the risks of 28-day and 90-day mortality decreased by 34 and $38 \%$, respectively for every $1 \mathrm{~g} / \mathrm{dL}$ increase in albumin. After adjusting all the covariates (model 3), the HR (95\% CI) of 28-day and 90-day mortality was 0.63 (95\% CI $0.50-0.80, p=0.0001)$ and 0.63 (95\% CI $0.51-0.78$, $p<0.0001$ ), respectively for each $1 \mathrm{~g} / \mathrm{dL}$ increase of albumin. To explore the nonlinearity of albumin regarding 28-day and 90-day mortality of critically ill AKI patients with CRRT, we also converted albumin into categorical variables (quartile) and found that $\mathrm{P}$ for the trend of albumin with 28-day and 90-day mortality of the patients was less than 0.01 (Table 4).

\section{The results of subgroup analyses}

A subgroup analysis was performed according to the CRRT indications. In the subgroup analysis based on the reasons for using CRRT, albumin was found to have a protective effect on the prognosis of patients with volume overload and metabolic acidosis. In patients with volume overload, the HR (95\% CI) of 28-day and 90-day mortality were $0.10(95 \%$ CI $0.02-0.39, p<0.001)$ and 0.15 (95\% CI $0.05-0.43, \mathrm{p}<0.001$ ), respectively for each $1 \mathrm{~g} / \mathrm{dL}$ increase in albumin after adjusting for all covariates. In patients with metabolic acidosis, the risks of 28day and 90-day mortality decreased with the increasing albumin, and the adjusted HR $(95 \% \mathrm{CI})$ was $0.24(95 \%$ CI $0.11-0.51, \mathrm{p}<0.001)$ and 0.28 (95\% CI $0.15-0.53, \mathrm{p}<$ 0.001 ), respectively (Table 5).

\section{Curve fitting analysis}

To investigate the relationship between albumin and prognosis in CRRT patients with critical AKI, we performed a fitting curve analysis. After adjusting age, sex, myocardial infarction, congestive heart failure, cerebrovascular disease, peripheral vascular disease, dementia,

Table 4 The results of multivariate Cox proportional hazards regression analysis

\begin{tabular}{|c|c|c|}
\hline Variable & 28-d mortality (HR 95\%Cl, p) & 90-d mortality (HR 95\%Cl, p) \\
\hline \multicolumn{3}{|l|}{ Model 1} \\
\hline Alb & $0.66(0.57,0.76)<0.0001$ & $0.62(0.55,0.71)<0.0001$ \\
\hline \multicolumn{3}{|l|}{ Alb(quartile) } \\
\hline Q1 & 1.0 & 1.0 \\
\hline Q2 & $0.93(0.73,1.18) 0.5395$ & $0.84(0.67,1.05) 0.1222$ \\
\hline Q3 & $0.75(0.59,0.96) 0.0219$ & $0.69(0.55,0.86) 0.0012$ \\
\hline Q4 & $0.56(0.43,0.72)<0.0001$ & $0.49(0.38,0.62)<0.0001$ \\
\hline$P$ for trend & $<0.0001$ & $<0.0001$ \\
\hline \multicolumn{3}{|l|}{ Model 2} \\
\hline Alb & $0.66(0.57,0.76)<0.0001$ & $0.62(0.55,0.71)<0.0001$ \\
\hline \multicolumn{3}{|l|}{ Alb(quartile) } \\
\hline Q1 & 1.0 & 1.0 \\
\hline Q2 & $0.92(0.73,1.17) 0.5021$ & $0.84(0.68,1.05) 0.1289$ \\
\hline Q3 & $0.75(0.59,0.96) 0.0220$ & $0.69(0.55,0.86) 0.0012$ \\
\hline Q4 & $0.55(0.43,0.72)<0.0001$ & $0.49(0.38,0.62)<0.0001$ \\
\hline$P$ for trend & $<0.0001$ & $<0.0001$ \\
\hline \multicolumn{3}{|l|}{ Model 3} \\
\hline Alb & $0.63(0.50,0.80) 0.0001$ & $0.63(0.51,0.78)<0.0001$ \\
\hline \multicolumn{3}{|l|}{ Alb(quartile) } \\
\hline Q1 & 1.0 & 1.0 \\
\hline Q2 & $0.71(0.50,1.02) 0.0622$ & $0.66(0.47,0.92) 0.0152$ \\
\hline Q3 & $0.62(0.44,0.88) 0.0076$ & $0.63(0.46,0.87) 0.0054$ \\
\hline Q4 & $0.52(0.35,0.76) 0.0008$ & $0.52(0.37,0.74) 0.0003$ \\
\hline P for trend & 0.0007 & 0.0006 \\
\hline
\end{tabular}

Model 1 adjust for: none

Model 2 adjust for: age; sex

Model 3 adjust for: age, sex, myocardial infarction, congestive heart failure, cerebrovascular disease, peripheral vascular disease, dementia, diabetes, hypertension, COPD, CRP, GFR, K+, HCO3-, phosphate, BMI, MAP, WBC, Hb, BUN, Cr, mechanical ventilation, CCI, APACHE II score, SOFA score, CRRT causes, AKI causes Q1:0.00-2.10, Q2:2.20-2.50, Q3:2.60-2.90, Q4:3.00-5.90 
Table 5 The results of subgroup analysis based on continuous renal replacement therapy (CRRT) causes

\begin{tabular}{|c|c|c|}
\hline Variable & $\begin{array}{l}\text { 28-d mortality (HR 95\%Cl, } \\
\text { p) }\end{array}$ & $\begin{array}{l}\text { 90-d mortality (HR 95\%Cl, } \\
\text { p) }\end{array}$ \\
\hline \multicolumn{3}{|c|}{ Volume overload } \\
\hline \multicolumn{3}{|c|}{ Model 1} \\
\hline Alb & $0.48(0.31,0.76) 0.0018$ & $0.45(0.28,0.71) 0.0006$ \\
\hline \multicolumn{3}{|c|}{ Model 2} \\
\hline Alb & $0.47(0.29,0.75) 0.0016$ & $0.45(0.28,0.71) 0.0006$ \\
\hline \multicolumn{3}{|c|}{ Model 3} \\
\hline Alb & $0.10(0.02,0.39) 0.0009$ & $0.15(0.05,0.43) 0.0005$ \\
\hline \multicolumn{3}{|c|}{ Metabolic acidosis } \\
\hline \multicolumn{3}{|c|}{ Model 1} \\
\hline Alb & $0.59(0.44,0.80) 0.0006$ & $0.61(0.47,0.80) 0.0003$ \\
\hline \multicolumn{3}{|c|}{ Model 2} \\
\hline Alb & $0.62(0.46,0.84) 0.0017$ & $0.63(0.49,0.83) 0.0008$ \\
\hline \multicolumn{3}{|c|}{ Model 3} \\
\hline Alb & $0.24(0.11,0.51) 0.0002$ & $0.28(0.15,0.53) 0.0001$ \\
\hline \multicolumn{3}{|l|}{ Oliguria } \\
\hline \multicolumn{3}{|c|}{ Model 1} \\
\hline Alb & $0.78(0.60,1.03) 0.0785$ & $0.76(0.59,0.96) 0.0227$ \\
\hline \multicolumn{3}{|c|}{ Model 2} \\
\hline Alb & $0.79(0.61,1.04) 0.0974$ & $0.76(0.60,0.97) 0.0290$ \\
\hline \multicolumn{3}{|c|}{ Model 3} \\
\hline Alb & $1.02(0.60,1.73) 0.9304$ & $0.89(0.56,1.41) 0.6301$ \\
\hline \multicolumn{3}{|c|}{ Hyperkalemia } \\
\hline \multicolumn{3}{|c|}{ Model 1} \\
\hline Alb & $0.66(0.37,1.20) 0.1734$ & $0.66(0.39,1.12) 0.1208$ \\
\hline \multicolumn{3}{|c|}{ Model 2} \\
\hline Alb & $0.70(0.39,1.28) 0.2514$ & $0.71(0.41,1.22) 0.2104$ \\
\hline \multicolumn{3}{|c|}{ Model 3} \\
\hline Alb & $--^{a}$ & $--^{a}$ \\
\hline \multicolumn{3}{|l|}{ Uremia } \\
\hline \multicolumn{3}{|c|}{ Model 1} \\
\hline Alb & $0.54(0.30,0.95) 0.0316$ & $0.33(0.19,0.58) 0.0001$ \\
\hline \multicolumn{3}{|c|}{ Model 2} \\
\hline Alb & $0.49(0.27,0.91) 0.0244$ & $0.33(0.19,0.59) 0.0001$ \\
\hline \multicolumn{3}{|c|}{ Model 3} \\
\hline Alb & $--^{a}$ & $--^{a}$ \\
\hline \multicolumn{3}{|l|}{ Other } \\
\hline \multicolumn{3}{|c|}{ Model 1} \\
\hline Alb & $0.73(0.54,0.98) 0.0386$ & $0.66(0.50,0.87) 0.0032$ \\
\hline \multicolumn{3}{|c|}{ Model 2} \\
\hline Alb & $0.74(0.55,1.00) 0.0467$ & $0.65(0.49,0.87) 0.0037$ \\
\hline \multicolumn{3}{|c|}{ Model 3} \\
\hline Alb & $0.44(0.25,0.79) 0.0058$ & $0.43(0.25,0.74) 0.0022$ \\
\hline
\end{tabular}

Model 1 adjust for: none

Model 2 adjust for: age; sex

Model 3 adjust for: age, sex, myocardial infarction, congestive heart failure, cerebrovascular disease, peripheral vascular disease, dementia, diabetes, hypertension, COPD, CRP, GFR, K+, HCO3-, phosphate, BMI, MAP, WBC, Hb, BUN, Cr, mechanical ventilation, CCl, APACHE II score, SOFA score, AKI causes

${ }^{a}$ : The model failed because of the small sample size 
diabetes, hypertension, COPD, CRP, GFR, K+, HCO3-, phosphate, BMI, MAP, WBC, $\mathrm{Hb}, \mathrm{BUN}, \mathrm{Cr}$, mechanical ventilation, $\mathrm{CCI}$, APACHE II score, SOFA score, CRRT causes, and AKI causes, it was found that with the increasing albumin, the risks of 28-day and 90-day mortality of patients decreased $(p<0.001)$ (Figs. 3 and 4 ).

\section{Discussion}

In this study, a negative correlation was depicted between albumin and the risks of 28-day and 90-day mortality in critically ill AKI patients with CRRT using a fully adjusted model. Also, the relationship between albumin and prognosis was different in patients with CRRT due to different causes.

Protein is the basic component of supporting life, and albumin accounts for approximately $40-60 \%$ of the total protein content in the body. It is primarily synthesized by the hepatocytes. It can regulate plasma colloidal osmotic pressure, maintain the blood vessel barrier, and act as a carrier to transport insoluble substances [2628]. The decrease of plasma albumin is caused by several pathological mechanisms, including decreased synthesis, increased decomposition, and redistribution of albumin [29]. Acute and chronic inflammation can affect liver protein metabolism through the inflammatory mechanism, reducing albumin synthesis and inducing an increase in capillary permeability; thus, reducing plasma albumin levels $[16,30]$. It is believed that the increase of albumin catabolism in hemodialysis patients induced by inflammation leads to hypoalbuminemia [17].
Thus, inflammation plays an important role in the occurrence and development of AKI [31]. AKI can lead to long-term effects of renal fibrosis and chronic inflammation and further progress to CKD [32, 33]. Also, albumin has a large number of reduced sulfhydryl groups; therefore, it has an antioxidant effect, which in excess can lead to kidney damage. Therefore, patients with reduced albumin are prone to AKI and CKD; thus, kidney function cannot recover in a short period and will increase the risk of death [30,34].

Several studies have shown that the decrease in serum albumin can predict the poor prognosis of the disease. A study by Olivia et al. in 486 severely burned patients demonstrated that albumin was a good predictor of burn mortality, with a reported area under the curve of 0.869 , and that the death risk increased by more than $80 \%$ when albumin level was below $2 \mathrm{~g} / \mathrm{dL}$ [35]. In Reza Behrouz's study, hypoalbuminemia was found to be independently associated with in-hospital mortality in patients with aneurysms subarachnoid hemorrhage, with an adjusted odds ratio (95\% CI) of 4.26 (95\% CI: 1.09 16.68, $p=0.04$ ) [36]. This study shows that albumin levels are associated with prognosis in critical patients with AKI under CRRT, which is consistent with the results of previous studies by Moon et al. [22]. However, more confounding variables were adjusted in this study to make the results more reliable. Simultaneously, the sensitivity analysis was also performed in the multivariate Cox regression analysis, and the nonlinear relationship between albumin and prognosis was observed to

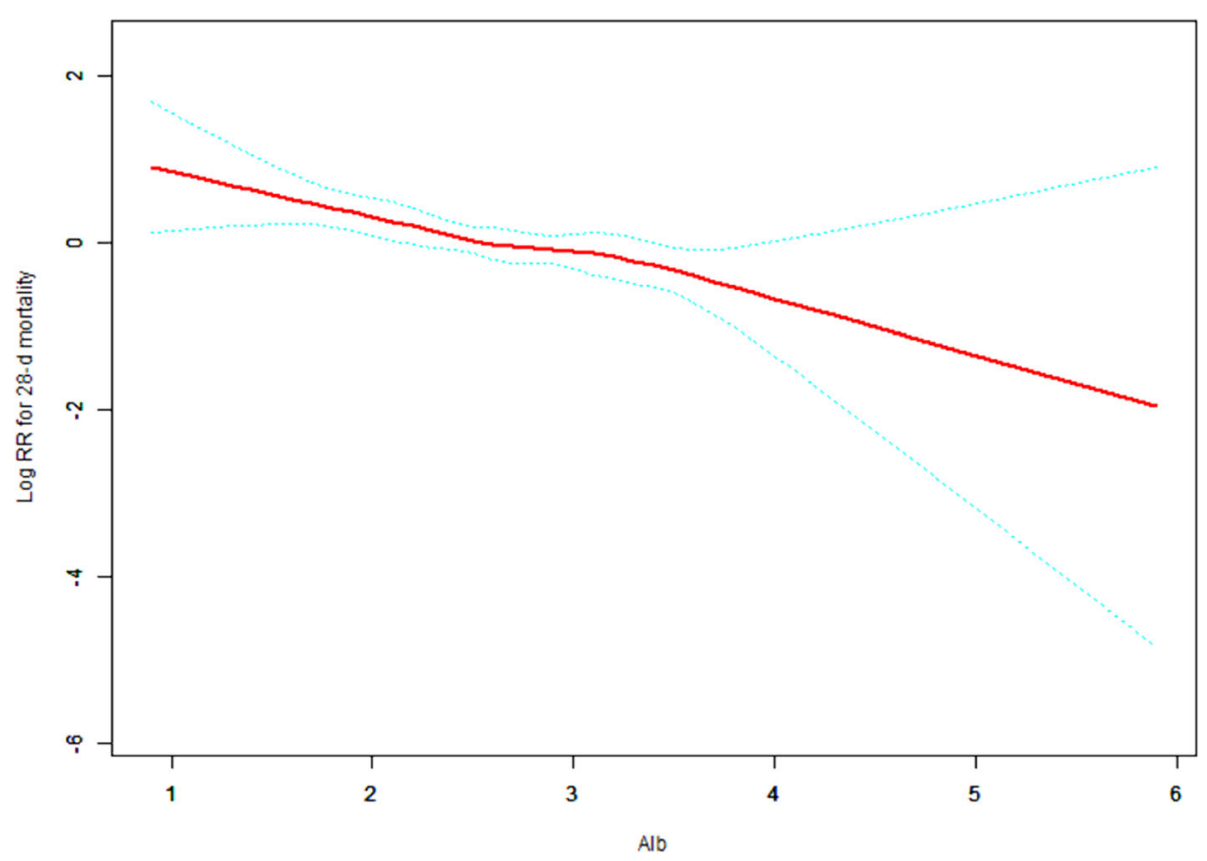

Fig. 3 Adjusted smoothing function of albumin for 28-d mortality 


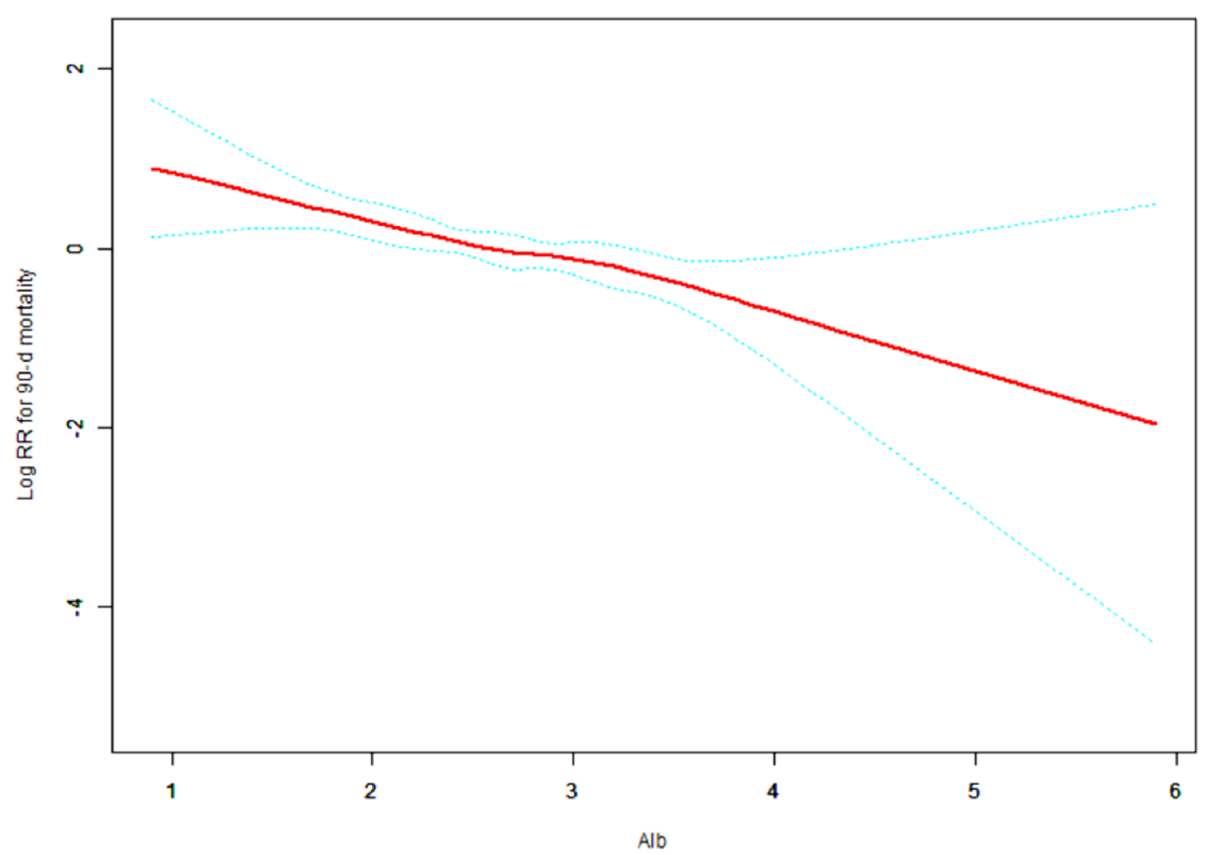

Fig. 4 Adjusted smoothing function of albumin for 90-d mortality

ensure the robustness of the results. Subgroup analysis based on CRRT indications demonstrated that some results were not significant or missing; however, the general trend was consistent. The subgroup possibly included fewer samples, which reduced the ability of the statistical system. Additionally, we observed that albumin was not associated with the risk of death in patients with oliguria. It is well-established that when renal function is impaired, the number of perirenal capillaries is reduced, and renal blood flow is greatly decreased, leading to reduced urine volume in patients [37]. Oliguria is a risk factor for poor prognosis in dialysis patients [21]. In patients with severe oliguria or anuria, the effect of decreased albumin on prognosis may be ignored. However, more research is needed to confirm the results.

There were some limitations in this study: 1) Our data were from Dryad's open database, and knowing whether patients received albumin infusion before CRRT was infeasible, which could affect albumin levels; thus, skewing the results; 2) Due to the limitations of the database, we could not know whether patients classified according to the etiology of AKI were mutually exclusive. So, the findings of this study needed to be further confirmed by large prospective studies.

\section{Conclusions}

In this study, we investigated the predictive value of hypoproteinemia in critical CRRT patients with poor prognoses. We also observed that albumin was not associated with prognosis in patients with oliguria.

\section{Abbreviations}

AKl: Acute kidney injury; CRRT: Receiving renal replacement therapy; $\mathrm{Cl}$ : Confidence interval; HR: Hazard ratio; ICU: Intensive care unit; IL: Interleukin; NO: Nitric oxide; VEGF: Vascular endothelial growth factor; AKIN: Acute Kidney Injury Network; BMI: Body mass index; CRP: C-Reactive protein; GFR: Glomerular filtration rate; HB: Hemoglobin; WBC: White blood cell; CR: Serum creatinine; BUN: Blood urea nitrogen; Alb: Albumin; HCO3: Bicarbonate; $\mathrm{K}+$ : Potassium; CCl: Charlson comorbidity index; SOFA: Sequential Organ Failure Assessment; APACHE II: Acute Physiology and Chronic Health Evaluation II; SD: Standard deviation; COPD: Chronic obstructive pulmonary disease

Acknowledgements

We are grateful to Jung et al. for opening up the data.

\section{Authors' contributions}

L.J.Z was involved in the study's formulation, design, data acquisition and analysis, and the drafting of the manuscript. W.M.J. and L.L.P help with data analysis. J.Y.P funded and oversaw the study. The final manuscript was read and approved by all authors.

\section{Funding}

This work was supported by the Medical Innovation Discipline of Zhejiang Province (Critical Care Medicine, Y2015).

\section{Availability of data and materials}

The data are obtained from the 'DataDryad' database (www.datadryad.org).

\section{Declarations}

Ethics approval and consent to participate

Because the data that were de-identified, the patient's written consent requirement was abandoned. The ethics committee of Yonsei University health system, Severance Hospital and Institutional Review approved the previous study. Therefore, it is also applicable to this study.

Consent for publication

Not applicable. 


\section{Competing interests}

There is no conflict of interest among the authors.

Received: 5 April 2021 Accepted: 27 August 2021 Published online: 08 September 2021

\section{References}

1. Lameire NH, Bagga A, Cruz D, De Maeseneer J, Endre Z, Kellum JA, et al. Acute kidney injury: an increasing global concern. Lancet (London, England). 2013;382(9887):170-9.

2. Mehta RL, Cerdá J, Burdmann EA, Tonelli M, García-García G, Jha V, et al. International Society of Nephrology's 0 by 25 initiative for acute kidney injury (zero preventable deaths by 2025): a human rights case for nephrology. Lancet (London, England). 2015;385(9987):2616-43. https://doi.org/10.1016/ S0140-6736(15)60126-X.

3. Hoste EA, Schurgers M. Epidemiology of acute kidney injury: how big is the problem? Crit Care Med. 2008;36(4 Suppl):S146-51. https://doi.org/10.1097/ CCM.0b013e318168c590.

4. Wald R, McArthur E, Adhikari NK, Bagshaw SM, Burns KE, Garg AX, et al. Changing incidence and outcomes following dialysis-requiring acute kidney injury among critically ill adults: a population-based cohort study. Am J Kidney Dis. 2015;65(6):870-7. https://doi.org/10.1053/.j.jkd.2014.10.017.

5. Iwagami M, Yasunaga H, Noiri E, Horiguchi H, Fushimi K, Matsubara T, et al. Choice of renal replacement therapy modality in intensive care units: data from a Japanese Nationwide administrative claim database. J Crit Care. 2015;30(2):381-5. https://doi.org/10.1016/j.jcrc.2014.11.003.

6. Guru PK, Singh TD, Akhoundi A, Kashani KB. Association of Thrombocytopenia and Mortality in critically ill patients on continuous renal replacement therapy. Nephron. 2016;133(3):175-82. https://doi.org/10.1159/ 000447543.

7. Chen X, Bai M, Zhao L, Yu Y, Yue Y, Sun S, et al. Time to peak bilirubin concentration and advanced AKI were associated with increased mortality in rheumatic heart valve replacement surgery patients with severe postoperative hyperbilirubinemia: a retrospective cohort study. BMC Cardiovasc Disord. 2021;21(1):16. https://doi.org/10.1186/s12872-020-018305.

8. Pistolesi V, Zeppilli L, Fiaccadori E, Regolisti G, Tritapepe L, Morabito S. Hypophosphatemia in critically ill patients with acute kidney injury on renal replacement therapies. J Nephrol. 2019;32(6):895-908. https://doi.org/10.1 007/s40620-019-00648-5.

9. Wang H, Kang X, Shi Y, Bai ZH, Lv JH, Sun JL, et al. SOFA score is superior to APACHE-II score in predicting the prognosis of critically ill patients with acute kidney injury undergoing continuous renal replacement therapy. Ren Fail. 2020;42(1):638-45. https://doi.org/10.1080/0886022X.2020.1788581.

10. Gburek J, Gołąb K, Juszczyńska K. Renal catabolism of albumin-current views and controversies. Postepy Hig Med Dosw (Online). 2011;65:668-77. https:// doi.org/10.5604/17322693.964329.

11. Ha CE, Bhagavan NV. Novel insights into the pleiotropic effects of human serum albumin in health and disease. Biochim Biophys Acta. 2013;1830(12): 5486-93. https://doi.org/10.1016/j.bbagen.2013.04.012.

12. González-Pacheco H, Amezcua-Guerra LM, Sandoval J, Martínez-Sánchez C, Ortiz-León XA, Peña-Cabral MA, et al. Prognostic implications of serum albumin levels in patients with acute coronary syndromes. Am J Cardiol. 2017;119(7):951-8. https://doi.org/10.1016/j.amjcard.2016.11.054

13. Xu JY, Chen QH, Xie JF, Pan C, Liu SQ, Huang LW, et al. Comparison of the effects of albumin and crystalloid on mortality in adult patients with severe sepsis and septic shock: a meta-analysis of randomized clinical trials. Crit Care (London, England). 2014;18(6):702.

14. Ancion A, Allepaerts S, Oury C, Gori AS, Piérard LA, Lancellotti P. Serum albumin level and hospital mortality in acute non-ischemic heart failure. ESC Heart Failure. 2017:4(2):138-45. https://doi.org/10.1002/ehf2.12128.

15. Soeters PB, Wolfe RR, Shenkin A. Hypoalbuminemia: pathogenesis and clinical significance. JPEN J Parenter Enteral Nutr. 2019;43(2):181-93. https:// doi.org/10.1002/jpen.1451.

16. Fleck A, Raines G, Hawker F, Trotter J, Wallace PI, Ledingham IM, et al. Increased vascular permeability: a major cause of hypoalbuminaemia in disease and injury. Lancet (London, England). 1985;1(8432):781-4.

17. Kaysen GA. Biochemistry and biomarkers of inflamed patients: why look, what to assess. Clin J Am Soc Nephrol. 2009:4(Suppl 1):S56-63. https://doi. org/10.2215/CJN.03090509.
18. Rabb H, Griffin MD, McKay DB, Swaminathan S, Pickkers P, Rosner MH, et al. Inflammation in AKI: current understanding, key questions, and knowledge gaps. J Am Soc Nephrol. 2016;27(2):371-9. https://doi.org/10.1681/ASN.201 5030261.

19. Wiedermann CJ, Wiedermann W, Joannidis M. Hypoalbuminemia and acute kidney injury: a meta-analysis of observational clinical studies. Intensive Care Med. 2010;36(10):1657-65. https://doi.org/10.1007/s00134010-1928-z.

20. Shao M, Wang S, Parameswaran PK. Hypoalbuminemia: a risk factor for acute kidney injury development and progression to chronic kidney disease in critically ill patients. Int Urol Nephrol. 2017;49(2):295-302. https://doi.org/1 0.1007/s11255-016-1453-2.

21. Wang IK, Wang ST, Lin CL, Chen TC, Chang HY, Kuo HL, et al. Early prognostic factors in patients with acute renal failure requiring dialysis. Ren Fail. 2006;28(1):43-9. https://doi.org/10.1080/08860220500461245.

22. Moon JJ, Kim Y, Kim DK, Joo KW, Kim YS, Han SS. Association of hypoalbuminemia with short-term and long-term mortality in patients undergoing continuous renal replacement therapy. Kidney Res Clin Pract. 2020;39(1):47-53. https://doi.org/10.23876/j.krcp.19.088.

23. Jung SY, Kwon J, Park S, Jhee JH, Yun HR, Kim H, et al. Phosphate is a potential biomarker of disease severity and predicts adverse outcomes in acute kidney injury patients undergoing continuous renal replacement therapy. PLoS One. 2018;13(2):e0191290. https://doi.org/10.1371/journal. pone.0191290.

24. Jung SY, Kwon J, Park S, Jhee JH, Yun HR, Kim H, et al. Phosphate is a potential biomarker of disease severity and predicts adverse outcomes in acute kidney injury patients undergoing continuous renal replacement therapy. Dryad Digital Repository. https://doi.org/10.5061/dryad.6v0j9 Accessed 20 Feb 2018.

25. Mehta RL, Kellum JA, Shah SV, Molitoris BA, Ronco C, Warnock DG, et al. Acute Kidney Injury Network: report of an initiative to improve outcomes in acute kidney injury. Crit Care (London, England). 2007; 11(2):R31.

26. Zeng R, Li D, Deng L, He Y, Sun X, Wan Z, et al. Hypoalbuminemia predicts clinical outcome in patients with type $B$ acute aortic dissection after endovascular therapy. Am J Emerg Med. 2016;34(8):1369-72. https://doi. org/10.1016/j.jem.2016.03.067.

27. Cabrerizo S, Cuadras D, Gomez-Busto F, Artaza-Artabe I, Marín-Ciancas F, Malafarina V. Serum albumin and health in older people: review and meta analysis. Maturitas. 2015;81(1):17-27. https://doi.org/10.1016/j.maturitas.2015. 02.009 .

28. Nazha B, Moussaly E, Zaarour M, Weerasinghe C, Azab B. Hypoalbuminemia in colorectal cancer prognosis: nutritional marker or inflammatory surrogate? World J Gastrointest Surg. 2015;7(12):370-7. https://doi.org/1 0.4240/wjgs.v7.i12.370

29. Franch-Arcas $\mathrm{G}$. The meaning of hypoalbuminaemia in clinical practice. Clin Nutr (Edinburgh, Scotland). 2001;20(3):265-9.

30. Levitt DG, Levitt MD. Human serum albumin homeostasis: a new look at the roles of synthesis, catabolism, renal and gastrointestinal excretion, and the clinical value of serum albumin measurements. Int J Gen Med. 2016;9:229-55. https://doi.org/10.2147/IJGM.S102819.

31. van Swelm RPL, Wetzels JFM, Swinkels DW. The multifaceted role of iron in renal health and disease. Nat Rev Nephrol. 2020;16(2):77-98. https://doi. org/10.1038/s41581-019-0197-5.

32. Chawla LS, Kimmel PL. Acute kidney injury and chronic kidney disease: an integrated clinical syndrome. Kidney Int. 2012;82(5):516-24. https://doi.org/1 0.1038/ki.2012.208.

33. Coca SG, Singanamala S, Parikh CR. Chronic kidney disease after acute kidney injury: a systematic review and meta-analysis. Kidney Int. 2012;81(5): 442-8. https://doi.org/10.1038/ki.2011.379.

34. Pavlakou P, Liakopoulos V, Eleftheriadis T, Mitsis M, Dounousi E. Oxidative stress and acute kidney injury in critical illness: pathophysiologic mechanisms-biomarkers-interventions, and future perspectives. Oxidative Med Cell Longev. 2017;2017:6193694-11. https://doi.org/10.1155/2017/6193 694.

35. Aguayo-Becerra OA, Torres-Garibay C, Macías-Amezcua MD, Fuentes-Orozco C, Chávez-Tostado Mde G, Andalón-Dueñas E, et al. Serum albumin level as a risk factor for mortality in burn patients. Clinics (Sao Paulo, Brazil). 2013; 68(7):940-5.

36. Behrouz R, Godoy DA, Topel CH, Birnbaum LA, Caron JL, Grandhi R, et al. Early hypoalbuminemia is an independent predictor of mortality in 
aneurysmal subarachnoid hemorrhage. Neurocrit Care. 2016;25(2):230-6. https://doi.org/10.1007/s12028-016-0259-5.

37. Kramann R, Tanaka M, Humphreys BD. Fluorescence microangiography for quantitative assessment of peritubular capillary changes after AKI in mice. J Am Soc Nephrol. 2014;25(9):1924-31. https://doi.org/10.1681/ASN.20131 01121.

\section{Publisher's Note}

Springer Nature remains neutral with regard to jurisdictional claims in published maps and institutional affiliations.

- fast, convenient online submission

- thorough peer review by experienced researchers in your field

- rapid publication on acceptance

- support for research data, including large and complex data types

- gold Open Access which fosters wider collaboration and increased citations

- maximum visibility for your research: over $100 \mathrm{M}$ website views per year

At BMC, research is always in progress. 